\title{
Squamous cell carcinoma developing in an epidermal inclusion cyst
}

\author{
Hubert Daisley Jr', Arlene Rampersad', Oneka Acco'1, Edmond Ramirez², \\ Dinelle Sirjuesingh ${ }^{3}$
}

${ }^{1}$ Department of Pathology, General Hospital, San Fernando, Trinidad. W.I, ${ }^{2}$ Department of Orthopaedy, University of The West Indies, St Augustine Trinidad. W.I, ${ }^{3}$ Department of Urology, University Of The West Indies St Augustine, Trinidad W.I

Corresponding author: Prof. Hubert Daisley jr, E-mail: profhdjr@yahoo.com

\begin{abstract}
Epidermal inclusion cysts and squamous cell carcinoma of the skin are very common pathological lesions. However a squamous carcinoma arising in an epidermal inclusion cyst is a rare finding. We present a case of the malignant transformation of an epidermal inclusion cyst into a squamous cell carcinoma over a 25 year period in a 67 year old male. A brief review of the literature and theories postulated as to its histiogenesis are undertaken.
\end{abstract}

Key words: Epidermal inclusion cyst; Malignant Transformation; Squamous cell Carcinoma.

\section{INTRODUCTION}

Epidermal inclusion cysts are the most common keratin containing cyst found in the skin leading sebaceous cysts and dermoid cysts. They are often referred to as implantion cysts since their major histiogenesis depends on the implantation of epidermis into the dermis following trauma. Carcinoma is ubiquitous, but rarely seen developing from the epithelium of epidermal inclusion cysts. Herein we report a case of a squamous cell carcinoma developing from an abdominal wall epidermal inclusion cyst.

\section{CASE REPORT}

\section{Case History}

A 67-year-old male was referred to the General Surgery outpatient clinic at the General Hospital in January for a left inguinal hernia. Five months later he developed a large painful abdominal wall exophytic ulcerated lesion with necrotic borders, which was located in the left upper quadrant of his abdominal wall.

One year prior to this event he was treated for benign prostatic hyperplasia by the Urological team and mention was made of a small palpable subcutaneous lump in the abdominal wall region which was the present location of this fungating mass. There were no raised skin lesions or plaques at this region seen by the Urological team, one year ago. The patient divulged that the subcutaneous lump being neither worrisome nor bothersome, was present for more than 20 years. A computed tomography of the patient's abdomen then revealed a $6.0 \mathrm{~cm} \times 2.2 \mathrm{~cm}$ cystic focus within the subcutaneous tissue of the left upper quadrant consistent with an epidermal inclusion cyst. A transabdominal ultrasound performed six months prior his death similarly described the lesion as a structure of mixed echogenicity $2.3 \mathrm{~cm} \times 1.0 \mathrm{~cm}$ (Fig. 1).

A wedge biopsy of the exophytic abdominal mass was performed under local anesthesia which was reported as a well differentiated squamous cell carcinoma occupying the dermis with sparing of the overlying epidermis. A metastatic squamous cell carcinoma to the region was entertained. The patient passed away suddenly a month after surgical biopsy of the exophytic mass and a post mortem examination was performed.

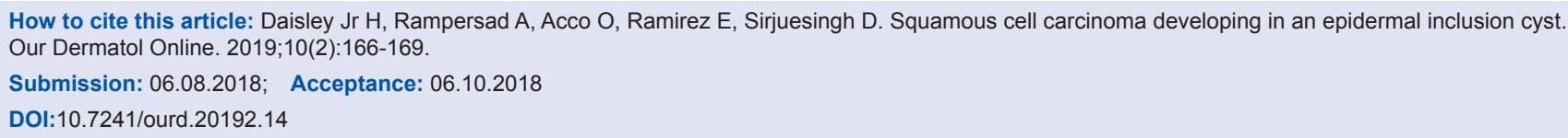




\section{Investigations}

At Post Mortem examination there was a $15 \mathrm{~cm} \mathrm{x}$ $11 \mathrm{~cm}$ raised nodular lesion with an ulcerated center in his left flank (Fig. 2). There was no communication seen between this abdominal wall mass and any of the abdominal or pelvic organs. A suitable section was taken for histological analysis. Gross examination of all internal organs found no evidence of distant or lymph node metastasis, or a primary site lesion.

Multiple sections of the autopsy specimen were examined which showed a well differentiated invasive squamous cell carcinoma not communicating from the overlying skin, with copious amounts of lamellar keratin, arising from the epidermal inclusion cyst wall. The neoplasm had invaded deep into the subcutaneous tissue. There was no evidence of the tumor arising from a skin appendage, but its origin from the epidermal cyst wall was clearly visible (Figs. 3 - 5).

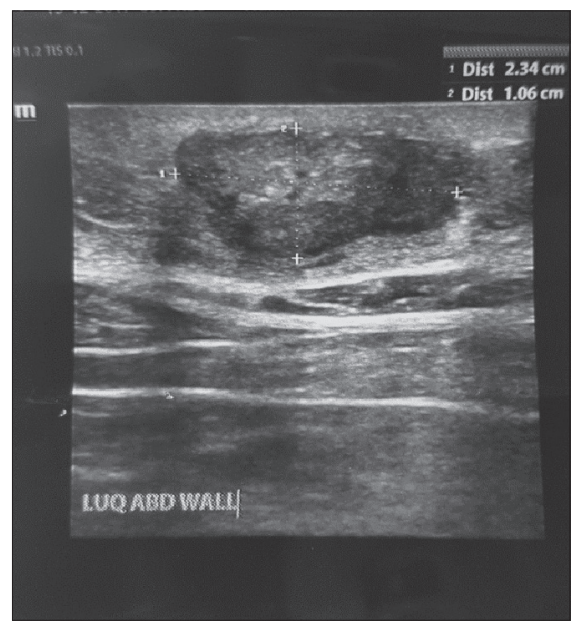

Figure 1: The ultrasonographic images of abdominal wall mass.

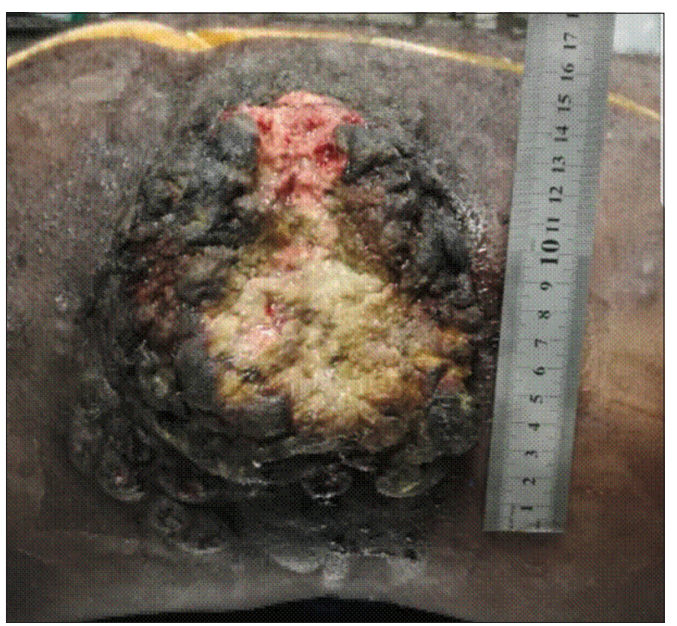

Figure 2: The post mortem images of abdominal wall mass.
Prior to the study, patient gave written consent to the examination and biopsy after having been informed about the procedure.

\section{DISCUSSION}

The figures above clearly demonstrate an invasive squamous cell carcinoma arising from an epidermal inclusion cyst. At autopsy a search for primary tumor sites were negative. Multiple sections of the tumor were examined but there was no indication that the squamous cell carcinoma had arisen from a skin appendage tumor [1]. This was not the case since at no time during the 20 plus years of the evolution of the neoplasm, was there any raised lesion on the skin at the site of development of the invasive squamous cell carcinoma.

Squamous cell carcinoma often arises in regions of the body exposed to ultra violet radiation [2] or

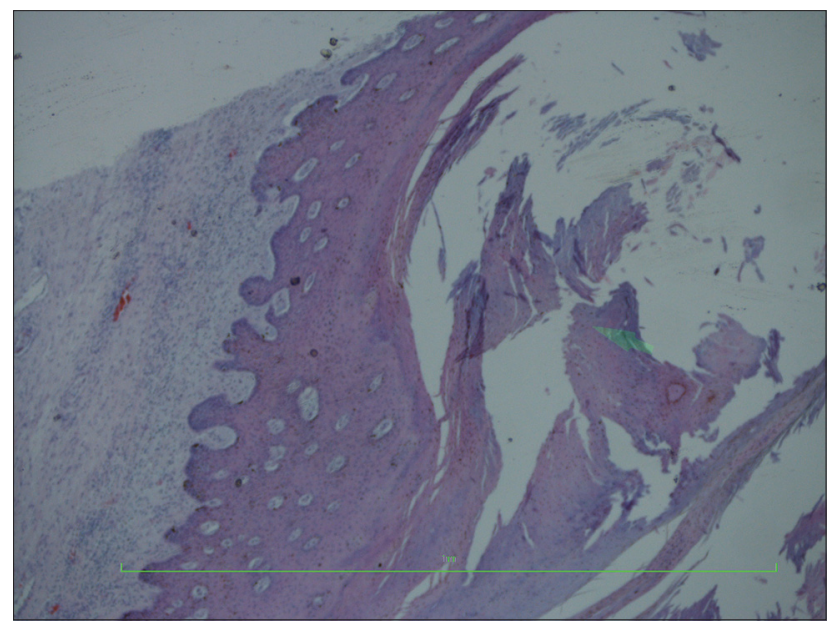

Figure 3: Epidermal inclusion cyst wall with lamellar keratin. H\&E

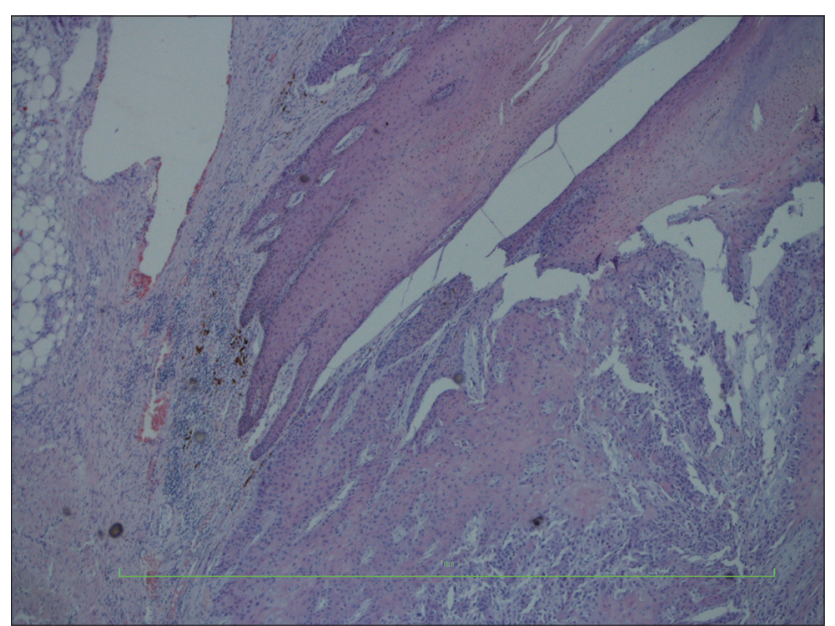

Figure 4: Malignant degeneration of the epidermal inclusion cyst wall. $\mathrm{H} \& \mathrm{E}$ 


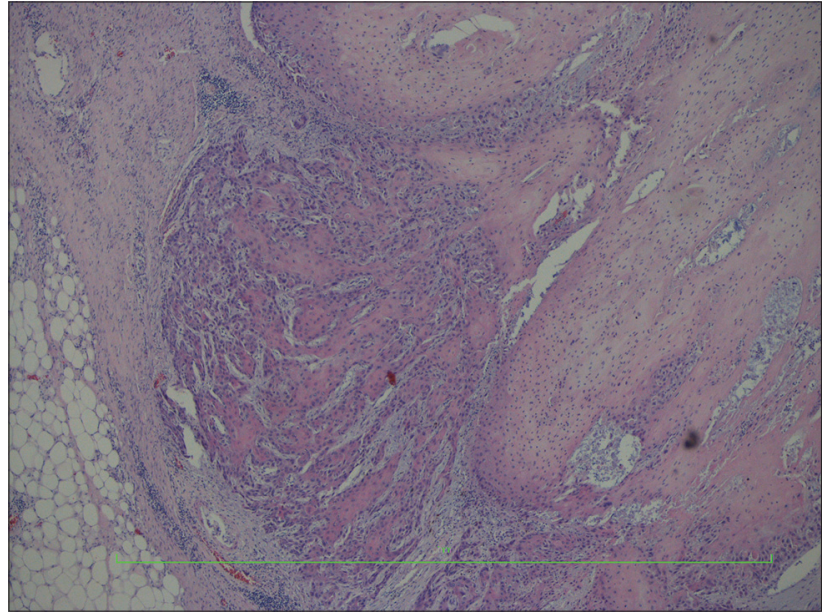

Figure 5: Well differentiated invasive squamous cell carcinoma developing in epidermal inclusion cyst wall. $\mathrm{H} \& \mathrm{E}$

regions of chronic irritation with repeated regeneration of squamous epithelium such as what occurs in a Marjolins ulcer [3].

The Human Papilloma Virus (HPV) also has a promoting role in squamous cell carcinogenesis [4]. It is most unlikely that ultraviolet radiation plays a role in inclusion cysts malignant transformation since these cysts are found distal to the dermis and are therefore not exposed to sunlight.

Chronic irritation most likely has a role in epidermal inclusion cysts malignant degeneration. Chronic irritation by squeezing produces an intense granulomatous reaction to keratin (Fig. 6). Probably this chronic irritation over a protracted number of years together with some unknown promoting factors, possibly HPV or genetic factors, are responsible for their malignant transformation.

Carcinogenesis is ubiquitous and it is therefore not surprising that other skin cancers have been reported to develop in epidermal inclusion cysts, but to a far lesser extent. Neoplasms such as Basal cell carcinoma, Mycosis Fungoides, Merkel Cell carcinoma and Melanomas have been reported to originate from epidermal inclusion cysts, but to a far lesser incidence than squamous cell carcinoma [1,5-7]. This may be so since the main promoting agent of these skin carcinomas, namely ultraviolet radiation, $[2,8]$ is not accessible to epidermal inclusion cysts in their deep dermal locations.

Squamous cell carcinoma developing in epidermal inclusion cysts are low in incidence with occurrence ranging from 0.011 to $0.045 \%$. [9]. It seems that

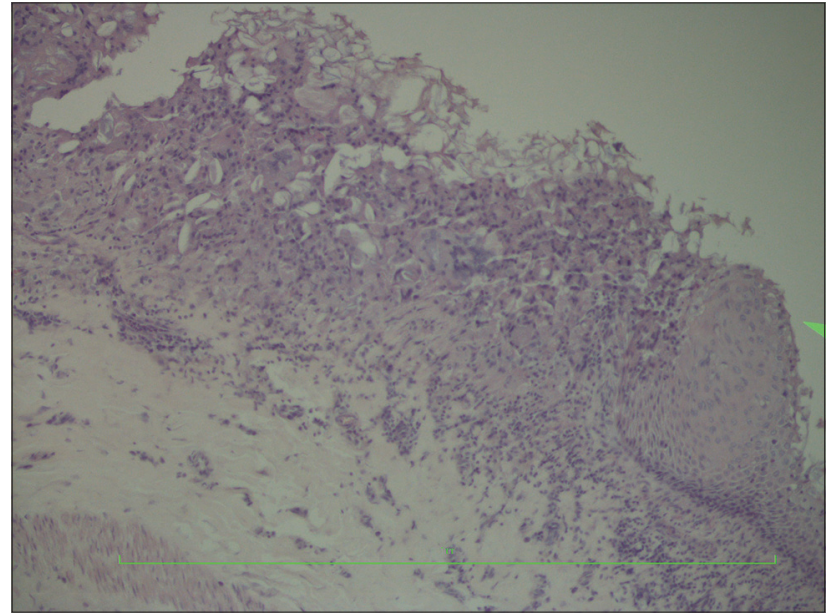

Figure 6: An epidermal inclusion that has ruptured producing a granulomatous reaction to keratin. H\&E

prolong chronic irritation, in this case 20 plus years, seems to be a major promoting factor. A rapid increase in size of an existing lesion is an ominous sign that malignant transformation of an epidermal inclusion cyst is occurring, and should also be considered when the cyst exhibits contrast enhancement on imaging [10]. It would be wise therefore to excise epidermal inclusion cysts wherever they are located and subject them to histological examination since malignant transformation can occur.

\section{CONCLUSION}

Epidermal inclusion cysts are common benign skin lesions. They should be excised and subjected to histological examination for malignant transformation, although rare, does occur. A rapidly increasing size of an existing inclusion cyst is an ominous sign that malignant transformation might be occurring.

\section{CONSENT}

The examination of the patient was conducted according to the Declaration of Helsinki principles

\section{REFERENCES}

1. Cotton D. Troublesome tumors 1: Adnexal tumors of the skin. J Clin Pathol. 1991; 44:543-48.

2. Martens MC, Seebode C, Lehmann J, Emmert S. Photocarcinogenesis and skin cancer prevention strategies: an update. Anticancer Res. 2018;38:1153-8.

3. Pekarek B, Buck S, Osher L. A comprehensive review on marjolin's ulcers: diagnosis and treatment. J Am Col Certif Wound Spec. 2011;3:60-4.

4. Westra WH. The changing face of head and neck cancer in the 


\section{www.odermatol.com}

$21^{\text {st }}$ century: the impact of HPV on the epidemiology and pathology of oral cancer. Head Neck Pathol. 2009;3:78-81.

5. Swygert KE1, Parrish CA, Cashman RE, Lin R, Cockerell CJ. Melanoma in situ involving an epidermal inclusion (infundibular) cyst. Am J Dermatopathol. 2007;29:564-5.

6. Aljufairi E, Alhilli F. Merkel Cell Carcinoma Arising in an Epidermal inclusion cyst. Am J Dermatopathol. 2017;39:842-4.

7. Li Liau J, Altamura D, Ratynska M, and Verdolinia R. Basal cell carcinoma arising from an epidermal cyst: when a cyst is not a cyst. Case Rep Dermatol. 2015;7:75-8.

8. Daya-Grosjean L1, Sarasin A. The role of UV induced lesions in skin carcinogenesis: an overview of oncogene and tumor suppressor gene modifications in xeroderma pigmentosum skin tumors. Mutat Res. 2005;571:43-56.
9. Anastasios K, Alexandra G, Anthony K, Efthimios S. Malignant transformation in a typical epidermal cutaneous cyst. J Med Case Rep. 2012;3:254-6.

10. Hoon Roh T, Sook Park Y, Yong Park Y, Hoon Kim S, Jong Chang H. Intracranial squamous cell carcinoma arising in a cerebellopontine angle epidermoid cyst: A case report and literature review. Medicine (Baltimore). 2017;96: e9423.

Copyright by Hubert Daisley Jr, et al. This is an open-access article distributed under the terms of the Creative Commons Attribution License, which permits unrestricted use, distribution, and reproduction in any medium, provided the original author and source are credited.

Source of Support: Nil, Conflict of Interest: None declared. 